\title{
Mobile Marketing in Small and Medium Hotel Enterprises
}

\section{Yousery Nabil Mohammed Kamel Elsayed}

\begin{abstract}
The mobile marketing revolution has had various impacts on the world travel market. It has supported small, medium and large hotel enterprises to reach their customers and to develop their customers' loyalty. The performance of small and medium hotel enterprises' (SMHEs) in relation to electronic marketing is different than large hotel enterprises. There is a paucity of research on mobile marketing of SMHEs, especially, in the Egyptian market. This research explores the adoption of mobile marketing by of Greater Cairo SMHEs using a mixed methods research approach. Semi-structured interviews and website content analysis were undertaken to reveal Greater the strengths and weaknesses of Cairo SMHEs. The research findings point to mobile phone calls and text messages as strong points in their performance but "mobile applications" was one of their weaknesses. The paper makes recommendations which should help SMHEs to advance their mobile marketing performance.
\end{abstract}

Keywords: Mobile Marketing; Mobile Applications; Small and Medium hotels; Greater Cairo Hotels; SMHEs strengths and weaknesses.

\section{Introduction}

The evolution of mobile devices has had a big impact on the marketing practices of customers and hotels. The mobile environment has become a major part of travelers' daily lives. Hotels have adopted mobile marketing applications to advance their relationships with customers, and to facilitate interaction with them. Hotel marketing campaigns have been customized to exploit mobile technology and various hotels, particularly chain hotels, e.g. Radisson, Mercure, Starwood, , which have developed their own mobile applications.. A key question is how have small and medium-sizes hotel enterprises (SMHEs) hve addressed the opportunities offered by mobile marketing applications, in the light of their poor financial resources. This paper presents the results of an investigation into the mobile marketing performance of SMHEs in Greater Cairo and reveals various areas for improvement. The research used a sequential process. Interviews with hotel owners and managers were followed by website analysis. The investigated 
hotels' websites and more than a thousand mobile applications were checked. The research results were analyzed to develop a set of recommendations. Time and geographical boundaries were part of the study limitations. The research pointed to opportunities for hoteliers in SMHEs to enhance their performance using free mobile application websites and hotel best practices. The research should lead to a series of future researches about mobile marketing in Egyptian hotels to maximize their revenues and enhance their relationship with their guests.

\section{Literature Review}

In 2003, Buhalis explained that mobile devices were a gradually-emerging major electronic distribution platform for tourism products. In the last decade, the role of mobile marketing has increased significantly in many markets as mobile communications technologies have become more affordable - third generation mobile phones have become widely spread around the globe and generation Y (i.e. people born between 1980 till 1990) has been described as a technology-oriented generation (Bolton et al., 2013; Abu-Elhassan et al., 2013). Globally, around 3.3 billion mobile phone technology users use mobile technology facilities (Lefebvre, 2013). The Experian (2013) study revealed that mobile phone accessibility to consumers between 18-34 years grew to reach 94\%. Accenture (2012) pointed also to another generation, reporting that $45 \%$ of people aged over 50 used mobile internet. Business travelers were early adopters of mobile travel technologies to address their need for flexible reservation facilities and information accessibility (World Travel Market, 2010).

Tourists en route have been characterised as active mobile technology users(Martin et al., 2011). This was asserted by ComScore Data Mine (2014), which pointed to travelers as mobile savvy users. Accenture (2014) surveyed 1475 executive officers in 14 countries who highlighted mobile devices as their as main digital platform. The same survey found 54\% of company leaders had a wide formal mobile strategy in their companies. This rapidly revolutionized the need for mobile technology strategies and tactics (e.g. websites optimized for mobile applications) from hoteliers to satisfy their updated customers' needs and to cope with this major shift in the market (World Travel Market, 2010).

Mobile marketing has a clear definition and its associated technologies, e.g.: mobile phone calls; text messages; mobile applications; multimedia messaging services; mobile-friendly websites, have been clearly identified (Mobile Marketing Association, 2008; World Travel Market, 2010; Lefebvre, 
2013). Mobile marketing has been defined as: "the use of wireless media as an integrated content delivery and direct response vehicle within a crossmedia or stand-alone marketing communications program" (Mobile Marketing Association, 2008: 22). Some applications are not commonly agreed to be mobile marketing tools, including: Advergames (Advertising mobile games as defined by Çeltek, 2010); mobile text chatting; mobile voice messages; mobile photo messages; mobile TV; LBS navigation services (location-based navigation services); video calls; virtual tour; second life (Hyun et al., 2009).

Hotels have launched their own mobile applications in many countries in response to the changing habits of consumers. The majority of British travelers $(53 \%)$ searched for hotels and resorts from mobile devices (ComScore Data Mine, 2014). A study in Croatia (Jakovic and Galetic, 2014) found that $20 \%$ of the researched hotel sample had mobile applications as their major mobile platforms, e.g. Google Play; Apple App Store; Windows Phone Market Place; Blackberry App World. The leading position of Google Play was confirmed by various stats and authors, e.g. Cocotas (2012), Dediu (2013), ComScore (2014).

The adoption of mobile marketing has pros and cons for each hotel case. For instance, the reasons for launching hotel mobile applications or refusing to publish mobile applications were identified by Adukaite et al. (2014). Their research investigated 4 and 5-star hotels in German-speaking European countries. They found the reasons for having mobile applications were limited to: increasing customer loyalty; promoting packages and special offers; enhancing interactions with hotel guests; providing more information about the visited destination. The same study revealed obstacles facing the widespread adoption of mobile applications in hotels, i.e.: poor knowledge; difficulty in calculating return on investment; funding problems to publish a hotel application. Dlodlo and Dhurup (2013) highlighted the main drivers controlling SMHEs' decision to adopt any electronic marketing applications (including mobile marketing) as: ease of use; external pressures; mission; job performance, resource availability and compatibility as significant drivers of e-marketing adoption in SMEs.

Research about SMHEs mobile marketing applications is very limited. Despite, mobile marketing and other electronic marketing techniques helping hotels to directly reach customers without using travel intermediaries (Stavrakantonakis et al., 2014). SMHEs' performance in electronic marketing varied widely according to their level of IT knowledge, and their financial resources. (Murphy and Kielgast, 2008; Dlodlo and Dhurup, 2013). 


\section{Research Methods}

The research was designed using a mixed methods research approach (Cresswell, 2003; Kalof et al, 2007) focusing on the mobile marketing applications adopted by Greater Cairo SMHEs. The following objectives were designed to achieve the research aim: 1) critically review relevant literature about mobile marketing and SMHEs; 2) survey the strengths and weaknesses of the mobile marketing practices adopted by Greater Cairo SMHEs; 3) develop recommendations to advance the adoption of mobile marketing applications by Greater Cairo SMHEs. A mixed methods research approach should enhance the quality of this research outcome and facilitate achieving its aim and objectives.

A case study methodology was adopted (Thomas, 2003; Yin, 2003; Woodside, 2010) on Greater Cairo SMHEs. The sample followed a purposive sampling technique (Madsen, 2011; Loveric, 2011). Three selection criteria were used for the sample: first, that the SMHE was located in one geographical area, i.e. Greater Cairo, to deal with same nature of guests. The second criterion was to have a website. A website was considered as one of the eCommerce business model applications (Turban et al., 2006).. The third criterion was to have less than fifty rooms (Coleman,2000;Main, 2001) . A snowball sampling technique (Corbetta, 2007) was used to increase the rate of response. The snowballing sample technique was useful to: increase the research accessibility; and to advance rate of response.

Data collection involved semi-structured interviews (Oppenheim, 1998; Gillham, 2005; Jennings, 2005) and website analysis (Yin, 2003; Sekaran and Bougie, 2009). Sequential procedures (Cresswell, 2003) were followed in this research. Semi-structured interviews with SMHEs managers and owners were followed by website analysis to expand the research findings. Using two research methods helped to enhance the understanding of the research findings (Kalof et al., 2008). The use of multiple research methods, additionally, increased the validity of the research findings (Cresswell, 2007). Website analysis involved two dimensions: the sample hotels' websites compatibility with Android mobile phones; investigating mobile applications on Google Play. The reason behind that was Android and Google Play represented the largest share in the mobile market environment (Cocotas, 2012; ComScore, 2014). The sample hotel names were searched on the Google play store, in addition to four other key words, i.e. Cairo Cheap Hotels; Cairo Budget Hotels; Cairo Hotels; Cairo Cheap Accommodation; These key words were used to reflect potential searches for cheap and budget accommodation in Cairo. Each mobile application result was examined to 
classify it as a SMHE, a chain hotel or a travel intermediary. This examination was helpful also to avoid unrelated results, such as games, general travel guides or travel information e,g. "Cairo Airport". These keywords and hotel names were searched to clarify how Greater Cairo SMHEs generally perform on the mobile applications market against other competitors.

The hotels' websites were visited and analyzed to check the mobile marketing applications. Discourse analysis (Krippendorf, 2004; Gillen and Peterson, 2007) was used to analyze the semi-structured interviews results. Qualitative and quantitative content analysis approaches were used to enrich the research results and to disclose more information about the mobile marketing environment for, and the adopted mobile marketing applications by, Greater Cairo SMHEs (Krippendorf, 2004; Kalof et al., 2008). The hotel names were coded. Each hotel name was replaced by $\mathrm{H}$ and followed by number, e.g. H1, H2...H11. The voluntary iformed consent form compelted byeach participatnt stated that hotel names would be coded so as not to reveal the interviewees' identities in the research results.

\section{Research Results and Discussions}

The researcher scanned all SMHEs in the Greater Cairo (The Egyptian Hotel Association, 2012) to meet the purposive sampling criteria. The researcher found 45 hotels with less than 50 rooms. The second criterion was to have a website. Only 10 of these 45 hotels had websites. Most SMHEs (35 hotels) did not have a website, which was considered as an indicator pointing to weak performance online. A website is an essential aspect of a hotel's online presence and a key part of the e-commerce model (Main, 2001; Essawy, 2004; Turban et al., 2006).

Snowball sampling helped to disclose another finding. In the purposive sampling, the researcher succeeded in interviewing five out of the targeted ten hotels. The snowballing sample helped to identify another 7 hotels that met the criteria. The finding was five SMHEs did not concern with including their websites in the Egyptian hotel association guide and 3 of these 5 hotels were not included in the list of published hotels. A total 12 hotels were included in the sample and interviewed. One hotel,, i.e. H4, was removed from the sample because its website was terminated after the interview. The final number of hotels investigated was eleven.

Greater Cairo SMHEs used the most highlighted mobile marketing applications. The majority (10 out of 11) of the investigated Greater Cairo SMHEs used mobile phones in telemarketing and to communicate with their 
guests and even their potential guests. Their belief in the importance of mobile marketing matched with those identified in the Experian (2013) report which highlighted mobile phones as a major means of communication for marketers. Lefebvre (2013) agreed with this finding and pointed to an increase in mobile phone users' talk time. $\mathrm{H} 9$ clarified how mobile phones played a major role to communicate with potential guests at critical times: "Mobile phone is critically important. I answer reservation requests or critical questions via calling my potential customers. I use this option frequently with short notice e-mails or reservation requests". Another hotelier (H5) did not use telemarketing but relied on e-mails since he believed in the ability of email to replace any regular call.

Text messages were the second major element used by SMHEs (8 out of 11). They considered it as a cheap and fast tool to market their services and to establish the relationships with their customers before his arrival or during his stay in the hotel. $\mathrm{H} 7$ stressed on its importance and gave an example for that: "Text messages are vital communication tool between hotels and their customers. For instance, we send a text message to our guests - straight after their flight arrival - to welcome our guests and to confirm we will pick up our guests from the airport". Lefebvre (2013) confirmed the importance of text messages and stressed the increasing numbers of text messages by mobile phone users. Ahanonou et al. (2013) research asserted its importance as the majority of mobile marketing campaigns were delivered via text messages. H1, H3 and H6 did not use text messages and relied on e-mails, voice calls or SKYPE technology. For instance, H3 did not like text messages as he believed in the power of voice calls to achieve a better marketing performance.

Mobile-friendly websites were identified as an upcoming important mobile marketing technique and to communicate with customers (Lefebvre, 2013). Greater Cairo SMHEs' performance varied from designing a mobile-friendly website and having some shortages. Only one hotel (H11) had two websites one was a standard mobile-friendly website and the other a regular website. The first website was specially designed for mobile phones. It was very simple in comparison to the second website which was the original website. Its mobile website included just six major icons without any pictures: "click to call"; "about us"; "rooms"; "facilities"; "find us"; "contact us". An additional four sub-icons were displayed on the website to reflect the following facilities:: "call"; 'Mail'; "Tweeter"; "Find us". The other website was designed for the desktop environment with pictures and provided much more information. Two hotels (H1 and H6) had only home pages. These two 
hotels offered only welcome messages about their hotels and did not have any other pages. A minority of SMHEs (4 out of 11) had reservation facilities on their websites. The remaining SMHEs (5 out of 11) offered essential information and pictures about their services and facilities. All the investigated SMHEs websites were managed by other companies or designers. Most SMHE hoteliers (9 out of 11) had not checked their websites' adaptability to mobile phones.

Multimedia message services and mobile banner advertisements did not inspire Greater Cairo SMHEs hoteliers. They identified them as extremely costly mobile marketing tools. All SMHEs hoteliers refused to use them. The reasons varied between lack of knowledge about information technology (H1); lack of financial resources $(\mathrm{H} 5 ; \mathrm{H} 6 ; \mathrm{H} 7$; H9; H11) or the hotel size (H5). H5 confirmed the last two reasons by saying: "They are too expensive. Large size hotels, like Marriott Cairo, can adopt these mobile marketing applications, but we cannot".

The mobile applications were difficult for SMHEs to launch. This finding was delivered by SMHEs hoteliers' words and the results of checking Google Play (see Table 1). None of the the Egyptian SMHEs interviewees were able to launch a mobile application for their hotels. H3 hotel announced - after the interview - on its website the existence of an iPhone application. The application was investigated, by visiting its website. The application was for an intermediary called "Hotel Concierge", not for H3 itself. The absence of mobile applications in the visions of SMHE marketers was confirmed after searching their hotels' names on Google Play website. The investigation process included searching for interviewees' hotels names followed by Cairo. The search also included searching the following key words to reveal any Cairo SMHEs ability to launch a mobile application. The additional key words searches undertaken were: "Cairo hotels"; "Cairo Hotel", "Cairo Budget hotels"; and "Cairo Cheap Hotels"; "Cairo Cheap Accommodation".

Interpreting Table 1 revealed various facts about Greater Cairo SMHEs; hotel chains and travel intermediaries. Greater Cairo SMHEs did not appear after investigating 1476 mobile applications results. Results of each key word were examined. Up to 100 Google Play results were checked for every key word. The total number of checked mobile applications was 1476 mobile applications.

Table 1 highlights the power of travel intermediaries in the Google Play market. The mean for online travel intermediaries was 30.2. The results were left skewed as the median was greater than the mean. The mode was 3 . The 
results had a high dispersion ( $\mathrm{SD}=24.2$ ). The only Egyptian travel intermediary which appeared was "Flying Carpet Tours". The chain hotels results were also left skewed and the mode was 1. The "Radisson Blu Cairo Hotel" continuously appeared in all key word searches. Chain hotels were performing more strongly than SMHEs in the mobile applications market.

Table No. 1: Mobile Applications Search Results

\begin{tabular}{|l|c|c|c|}
\hline & Greater Cairo SMHEs* & Hotel Chains & Travel Intermediary \\
\hline Mean & 0 & 6.3 & 30.2 \\
\hline Median & 0 & 7.6 & 35.6 \\
\hline Mode & 0 & 1 & 3 \\
\hline SD & 0 & 5.2 & 24.2 \\
\hline
\end{tabular}

* SMHEs (Small and Medium Hotel Enterprises)

The leading mobile applications for chain hotels and travel intermediaries varied for each key word. The research results pointed to the following hotel chain applications: Novotel Hotels; Mercure Hotels; Choice hotels; Radisson Blu Cairo; Premiere Inn Hotels; NH Hotels reservations; Drury Hotels; SPG Starwood Hotels and resorts; Centara hotels and resorts; Sofitel/luxury Hotels; Rotana Hotels; Atlantica Hotels; Rixos Hotels; H10 Hotels.

The top travel intermediaries results for mobile applications included: "hotel tonight"; "hotel finder"; "hotel booking: hotels"; "Cairo Guide Map Hotel Weather"; "Hotel Quickly"; "Hotels"; "Expedia"; "Orbitz"; Priceline Hotels and Travel"; "Travelocity"; "Hotel Deals"; "Touc Hotel"; "Hotel Search"; "Hotels" (Hotwave travel); "Hotels"(AandA); "Hotels combined"; "Hotels By Me"; Hotels fairy; "Booking Hotel".

SMHE hoteliers neglected mobile applications. This result was justified by $\mathrm{H} 2$ who stated: "Mobile Applications cost a lot of money. My hotel size and the hotel's financial resources could not allow me to do it". H7 agreed with $\mathrm{H} 2$ and stated a figure to represent his monthly advertising expenses: "We refused many offers to launch a mobile application. How I can launch a mobile application when my monthly advertising budget is around 500 LE" Financial barriers were also highlighted by Main (2001) and Murphy and Kielgast (2008), who pointed to it as a major constraint - for SMHEs hoteliers - against adopting modern technologies and to let them follow the updated marketing trends. 
The research findings exposed strengths for Greater Cairo SMHEs as: using mobile phones call; text messages; designing websites to be easily browsed by mobile phones. One hotel (H3) started to believe in the importance of mobile applications and published a travel intermediary's mobile application on his website. Greater Cairo SMHEs need more efforts in the following areas: mobile applications and designing a mobile friendly website. The nature of SMHEs could not let them apply other mobile marketing applications, e.g. mobile banner ads, which represent a lost opportunity in relation to increasing customers' loyalty and promoting special offers.

\section{Recommendations and Conclusions}

The global spread of mobile devices and the changing nature of customers' requires a better strategy to satisfy modern-day travellers. Therefore, Greater Cairo hoteliers need to develop and sustain their mobile marketing advantages and to advance certain areas in their mobile marketing performance, i.e. mobile applications and the development of more mobilefriendly websites. These aspects could be addressed through adopting the following recommendations: 1 . Greater Cairo SMHEs needed to publish their website widely, e.g. using the Egyptian Hotel Association guide; 2. Hotel websites needed to be mobile-friendly loaded with essential information (e.g. contact details and reservation facilities) to support a healthy relationship with potential customers; 3 . Mobile applications should be developed in a way which enhances the position of SMHEs against hotel chains and travel intermediaries; 4. Greater Cairo SMHEs should sustain using mobile voice calls and text messages as leading mobile marketing applications.

\section{Research Implications and Limitations}

The research points to mobile-friendly websites and mobile applications as areas needing improvement in SMHEs in Greater Cairo. Mobile applications could be enhanced by using free mobile application designing websites. An example for these websites was a website called www.ibuildapp.com. These websites help to design mobile applications, or even to let hoteliers share (via Bluetooth) their designed applications with their guests, without paying any fee for hosting their mobile applications. The other area needing advancement was designing a mobile-friendly website. H11's mobilefriendly website was a good example to guide other hoteliers to launch their own mobile-friendly websites. Egyptian hoteliers could use these research 
findings to advance their performance and achieve better mobile marketing results.

The geographical boundary was a limitation of this research as the research dealt only with Greater Cairo. The time and funding issues were other factors affecting the research design. These three limitations influenced the research design. These limitations did not enable the researcher to compare between various geographical areas in Egypt or in other countries, which should need further funding to travel and more time.

\section{Future Research}

The study findings initiated new areas for research. "Mobile applications" and "mobile-friendly websites" can be suggested for further studies. Two particularly good examples of well-performing mobile-friendly websites in Egypt were: "Radisson Blu Cairo Hotel" and "Flying Carpet Tours". These could be included in the samples of upcoming studies to promote their good practice.

Other geographical areas and sizes of hotel enterprises could be suggested to undertake future research for further explorations of mobile marketing applications. These could help to develop a toolkit for designing successful mobile marketing strategies.

\section{References}

Abu-Elhassan, A.E., Elsayed, Y.N.M.K., Soliman, D.M. (2013). The Influences of Modern Technologies on Generations' Job Satisfaction: Luxor Hotels Case Study. Journal of faculty of Tourism and Hotels Fayoum University. Volume 7, issue 2, 2013.

Accenture (2012). Mobile Web Watch 2012. Accenture. Available at: www.accenture.com/us-en/Pages/index.aspx [Accessed on: 22 January 2014].

Accenture. (2014). Accenture Mobility Insights Report 2014: Mobility: Fueling the Digital Surge. Accenture. Available at: http://www.accenture.com/ SiteCollectionDocuments/ PDF/AccentureMobility-Research-Report-2014.pdf [Accessed On: 23 May 2014].

Adukaite, A., Reimann, A. M., Marchiori, E. and Lorenzo Cantoni, L. (2014). Hotel Mobile Apps. The Case of 4 and 5 Star Hotels in European German-SpeakingCountries. In: Z. Xiang and I. Tussyadiah (Eds.). Information and Communication Technologies in Tourism 2014: Proceedings of the International Conference in Dublin, Ireland, January 21-24, 2014. Springer International Publishing. PP: 45-57 
Ahanonou, K., Biggerstaff, P., Flacuks, A., Hatfield, M., Nahman, M., Seal, K., Tram, T., Woods, K., and Yerelianet, D. (2013). Mobile Brand Interaction in Southeast Asia: A Comparative Study. IJMM. Winter 2013. Vol. 8, No.

2. PP: 5-18.

Bolton, R.N., Parasuraman, A., Hoefnagels,A., Migchels, N., Kabadayi, S., Gruber, T., Loureiro, Y.K. and Solnet, D. (2013). Understanding Generation Y and their use of Social Media: a Review and Research Agenda. Journal of Service Management. Vol. 24 No. 3. pp. 245-267

Buhalis, D. (2003). E Tourism: Information Technology for Strategic Tourism Management. Prentice Hall.

Coleman, P.D. (2000). A Study of Knowledge, Attitudes and Behaviour with Regards to Food Safety, in the Welsh Hospitality and Catering Industry. PhD Thesis. University of Wales Institute Cardiff (UWIC). PP: 52- 62..

Çeltek, E. (2010). Mobile Advergames in Tourism Marketing. Journal of Vacation Marketing. Vol.16, No.4. PP: 267-281

Cocotas, A. (2012). CHART: Android Dominates Mobile Platform Market Share. Business Insider. Available at: http://www.businessinsider.com/mobile-platform-market-share-2012-8 [Accessed on: 24 May 2014].

ComScore (2014). ComScore Reports January 2014 U.S. Smartphone Subscriber Market Share. Insights. Available at: https://www.comscore.com/Insights/ Press_Releases/2014/3/comScore_Reports_January_2014_US_Smartphone_ Subscriber_Market_Share [Accessed on: 25 May 2014]. ComScore Data Mine. (2014). UK Travel Consumers Go Mobile. Available at: http://www.comscoredatamine.com/2014/05/uk-travel-consumers-gomobile/ [Accessed on: 25 May 2014].

Corbetta, P. (2003). Social Research: Theory, Methods and Techniques. Sage Publications. London. United Kingdom. PP: 269-274.

Cresswell, J.W. (2003). Qualitative, Quantitative and Mixed Methods Approaches. $2^{\text {nd }}$ Edition. Sage Publications, Inc.

Cresswell, J.W. (2007). Qualitative Inquiry \& Research Design: Choosing Among Five Approaches. Second Edition. Sage Publications, Inc. PP: 202209.

Dlodlo, N. and Dhurup, M. (2013). Drivers of E-Marketing Adoption among Small and Medium Enterprises (SMEs) and Variations with Age of Business Owners. Mediterranean Journal of Social Sciences. Vol. 4, No.14. PP.53- 66. 
Egyptian Hotel Association. (2012). The Egyptian Hotel Guide 2011-2012. $32^{\text {nd }}$ Edition. Egyptian Hotel Association.

Essawy, M.T. (2004). Competing in the Digital Market: A Framework for Probing the Effectiveness of the Online Relationship Marketing of Hotel Chains. In: E. Jones and C. Haven (Eds.). Proceedings of the First Combined CHME Hospitality Research and CHME Learning and Teaching Conference 25th Birthday Celebrations April 14th-16th 2004. UWIC Press. PP: 259-268. Experian (2013). The 2013 Digital Marketer: Life is the Channel. The Experian Marketing Services.

Gillen, J. and Peterson, A. (2007). Discourse Analysis. In: B. Somkh and C. Lewin (Eds.). Research Methods in The Social Sciences. Sage Publications, Ltd. PP: 146-153.

Gillham, B. (2005). Research Interviewing: the Range of Techniques. Open University Press, McGraw Hill Edition. PP: 34.

Hall, C. M. and Valentin, A. (2005). Content Analysis. In: B. W. Ritchie, P. Burns and C. Palmer (Eds.). Tourism Research Methods: Integrating Theory with Practice. Cabi Publishing. PP: 191- 209.

Hyun, M.Y., Lee, S. and Hu, C. (2009). Mobile-mediated Virtual Experience in Tourism: Concept, Typology and Applications. Journal of Vacation Marketing. Vol. 15, No. 2. PP: 149-164.

Jakovic, B. and Galetic, F. (2014). Marketing and Commercial Activities Offered on Croatian Five-Star Hotel Web Sites. Procedia Engineering. Vol. 69. PP: $112-120$.

Jennings, G.R. (2005). Interviewing: a Focus on Qualitative Techniques. In: B.W. Ritchie, P. Burns and C. Palmer (Eds.). Tourism Research Methods: Integrating Theory with Practice. Cabi Publishing. PP:99-117.

Lefebvre, C. (2013). Social Marketing and Health Communication: Integrating Cell Phones and Mobile Technologies into Public Health Practice: A Social Marketing Perspective. Health Promotion Practice. October 2013. Vol.10, No.4. PP: 490 - 494.

Kalof, L., Dan, A. and Dietz (2008). Essentials of Social Research. Open University Press. Berkshire, England. PP: 135-143.

Krippendorf, K. (2004). Content Analysis: An Introduction to its Methodology. $2^{\text {nd }}$ Edition. Sage Publications. P: 5-17.

Lovric, M. (2011). "International Encyclopedia of Statistical Science. Springer.

Madsen, B. (2011). Statistics for Non-Statisticians. Springer.

Main, C. H. (2001). The Use of the Internet by Hotels in Wales. A Longitudinal Study from 1994 to 2000 of Small and Medium Enterprises in a 
Peripheral Location with a Focus on Net Technology. In: P.J. Sheldon, K.W. Wober and D.R. Fesenmaier (Eds). Information and Communication Technologies in Tourism 2001: Proceedings of the International Conference in Montreal, Canada. Springer Wien. New York. PP:214-223.

Martin, D., Alzua, A. and Carlos L.C. 2011. Contextual Geofencing Mobile Tourism Service. In: R. Law, M.Fuchs and F. Ricci (Eds.) Information and Communication Technologies in Tourism 2011: Proceedings of the International Conference in Innsbruck, Austria, January 26-28, 2011. Springer Wien. PP: 255- 267.

Maxwell, J.A. (1998). Designing a Qualitative Study. In: L. Bichman and D. J. Rog (Eds.). Handbook of Applied Social Research Methods. Sage Publications, California, USA. PP: 69-100.

Mobile Marketing Association (2008). Mobile marketing industry glossary. Version 2008. 12. Mobile Marketing Association. PP: 22. Available at: http://mmaglobal.com/glossary.pdf [Accessed on: 24 May 2014].

Murphy, H. C and Kielgast, C. D. (2008). Do Small and Medium-Sized Hotels Exploit Search Engine Marketing, International Journal of Contemporary Hospitality Management. Vol. 20, No. 1. pp. 90-97.

Oppenheim, A.N. (1998). Questionnaire Design, Interviewing and Attitude Measurement. New Edition. Cassell. London. PP: 66- 117.

Sekaran, E. and Bougie, R. (2009). Research Methods for Business: A Skills Building Approach. 5th Edition. John Wiley and Sons, Inc.

Stavrakantonakis, I., Toma, I. Fensel, A. and Fensel, D. (2014). Hotel Websites, Web 2.0, Web 3.0 and Online Direct Marketing: The Case of Austria. In: Z. Xiang and I. Tussyadiah (Eds.). Information and Communication Technologies in Tourism 2014: Proceedings of the International Conference in Dublin, Ireland, January 21-24, 2014. Springer International Publishing.

Turban, E., King, D., Lee, J. and Viehland, D. (2006). Electronic Commerce: A Mangerial Perspective 2006. Pearson Education, Inc. PP: 118.

Thomas, R. M. (2003). Blending Qualitative and Quantitative Research Methods in Theses and Dissertations. Corwin Press.

Woodside, A. G. (2010). Case Study Research: Theory, Methods, Practice. Emerald Group Publishing Limited.

World Travel Market. (2010). WTM Global Trends Reports 2010. World Travel Market 8-10 November 2010 Excel London. Available at: www.wtmlondon.com [Accessed on: 24 January 2014].

Yin, R.K. (2003). Case Study Research : Design and Methods. 3rd Edition. Sage Publications. London, United Kingdom. PP: 100-123. 


\section{التسويق المحمول فى الفنادق الصغيرة و المتوسطة

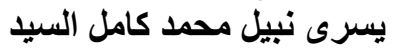 \\ كليه السياحة والفنادق - جامعة طلوان}

احدث التسويق المحمول ثورة فى سوق السفر العالمى و تعددت أثناره. و من مز الياه للفندقيين مساعدة

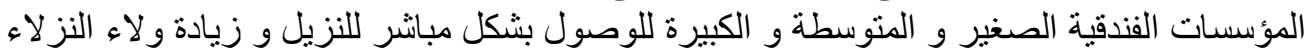

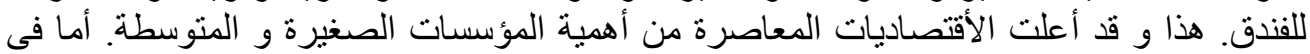

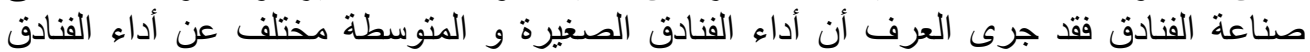

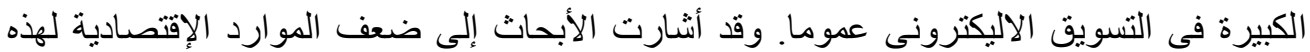

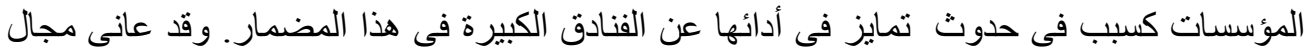

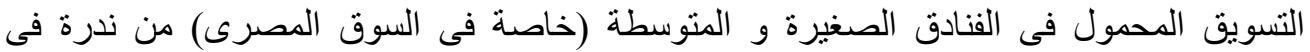

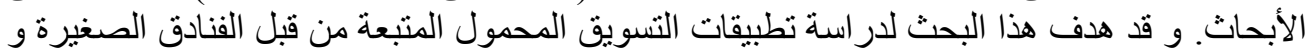

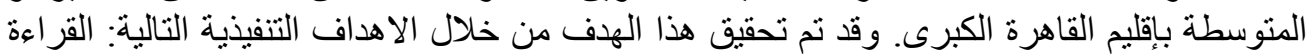

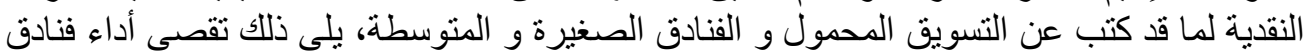

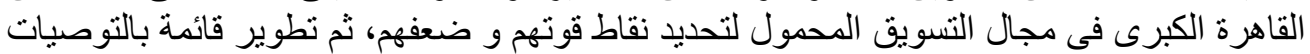

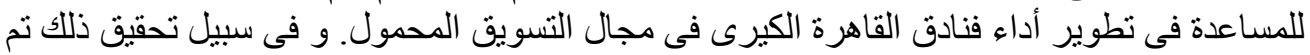

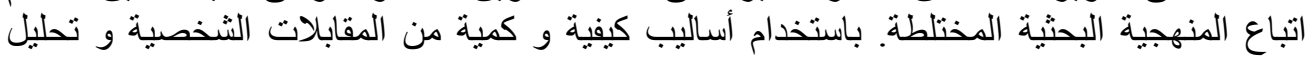

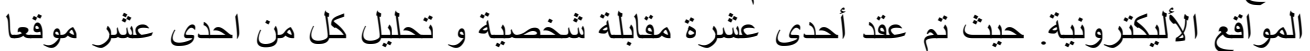

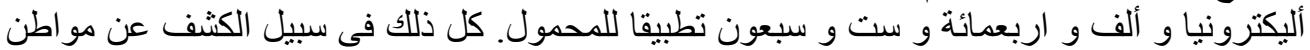

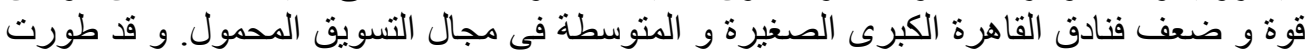

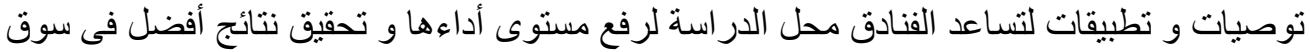

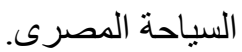

